\title{
Prevalence of Non-Screening for Colorectal Cancer: Comparing a Rural State to the United States
}

\author{
Abhilash Perisetti ${ }^{1}$, Hafiz Khan ${ }^{2 *}$, Rachana Yendala ${ }^{6}$, Nayana E George ${ }^{4}$, Saikiran Raghavapuram ${ }^{4}$,Aamrin Rafiq ${ }^{3}$, \\ Summre Blakely ${ }^{2}$, Nathan Villalpando ${ }^{2}$, Drew Rasmussen ${ }^{2}$, and Hemant Goyal ${ }^{5}$ \\ ${ }^{1}$ Department of Family and Community Medicine, Texas Tech University Health Sciences, Lubbock, TX \\ ${ }^{2}$ Department of Public Health, Texas Tech University Health Sciences, Lubbock, TX \\ ${ }^{3}$ Department of Mathematics \& Statistics, Texas Tech University, Lubbock, TX \\ ${ }^{4}$ Department of Internal Medicine, University of Arkansas Medical Sciences, Little Rock, AR \\ ${ }^{5}$ Mercer University School of Medicine, Macon, GA \\ ${ }^{6}$ Department of Hematology and Oncology, Texas Tech University Health Sciences, Lubbock, TX
}

Received: March 28, 2018; Accepted: April 23, 2018; Published: May 07, 2018

*Corresponding author: Hafiz Khan, 3601 4th Street STOP 9430, Lubbock, TX 79430-9430, Tel. 806-743-4213; E-mail: hafiz.khan@ttuhsc.edu

\begin{abstract}
Background: The incidence and mortality of Colorectal Cancer (CRC) in North Dakota (ND) areamong the highest in the United States (US). In addition, screening rates for CRC in ND have remained consistently lower than that of the nation in recent years. This study aims to (1) determine the predictors of non-screening of CRC;(2) compare the prevalence of self-reported CRC screening among ND and US populations; and (3) identify the high-risk geographical areas for possible future CRC prevention initiatives.
\end{abstract}

Methods: We used data of 232,429 adults (aged 50-75 years) who had an annual physical examination from the 2010 Behavioral Risk Factor Surveillance System (BRFSS) to describe individuals who never received CRC screening.

Results: CRC non-screening rateswere significantly higher among North Dakotans than the rest of the US population $32 \%$ vs. $27 \%$; $p<0.0001$ ). ND individuals who were 50 to 64 years old ( $38 \%$ vs. $32 \%$; $p<0.0001)$, individuals living in rural ND (39\% vs. $25 \% ; p<0.0001)$ and lack of insurance (ND: $62 \%$ vs. US: $57 \%$ ) were less likely to report CRC screening than the U.S. population. Adjusting for multiple variables, ND individuals were significantly less likely to report CRC screening (aOR=0.74; 95\% CI [0.66-0.83]) than the U.S. respondents.

Conclusions: The prevalence of individuals who never received CRC screening in ND is higher than in the U.S. Interventions tailored towards individuals with a lower education, living in a rural area, and lacking a personal doctor and health insurance could enhance CRC screening.

Keywords: Colorectal cancer, Screening, BRFSS, Secondary prevention, Epidemiology

\section{Introduction}

Colorectal Cancer (CRC) is one of the leading causes of cancerrelated mortality in the United States. It ranks second to breast cancer in women and lung cancer in men [1]. In 2017 alone, there are expected to be 135,540 new cases of CRC[2]. Additionally, there will be an expected 50,260 deaths in 2017 due to CRC comprising of $8.4 \%$ of all cancer-related deaths.The risk of CRC is higher in men (1 in 21 men will be diagnosed as compared to 1 in 23 women), it affects both genders significantly [2]. CRC has a tremendous financial impact on the patients, their families and the whole society. In the year 2010 , roughly $\$ 14$ billion were spent on direct medical costs of CRC in the US [3].Effective screening detects pre-cancerous or early cancerous lesions which could be effectively treated [4]. Preventative screening for CRC can reduce the cancer-related death by almost $50 \%$ in these patients [4]. The United States Preventive Services Task Force (USPTF) recommends that women and men ages 50 to 75 either receive a Fecal Occult Blood Test (FOBT) each year, receive a sigmoidoscopy every 5-years and a FOBT every 3 years each, or receive a colonoscopy every 10 year[5]. On average, people with higher education and income are more likely to be screened for CRC [4]. However, screening rates for CRC was only $63 \%$ in 2015 in the US [2-4, 6]. Barriers to CRC screening include embarrassment and fear of invasive procedures, a lack of awareness of screening, a lack of awareness about CRC at all, a lack of access to healthcare services in general, a lack of financial resources and/or health insurance, and lack of a health care provider [7-8]. The National Colorectal Cancer Roundtable (NCCRT), a coalition of over 1500 organizations, has set forth an ambitious target to reach screening rate of $80 \%$ in the U.S. by 2018 called " 80 by 2018 initiative"[9]. To attain this goal, the NCCRT has planned to motivate patients to consider screening, create key partnerships with community health centers, improve access to screening, and accurately evaluate the progress of the initiative and its success [9]. If the NCCRT reach its goal, an estimated 277,000 CRC cases and 203,000 CRC-related deaths can be prevented by 2030 [9]. 
Rates of CRC screening vary among different regions being lower in the West and South, and higher in the Midwest and East regions of the US [4]. Rural regions often face more barriers to health care access in general as well as barriers to screening [7]. According to a study in 2015 which evaluated the differences between CRC screening rates in rural and urban Nebraska, rural residents were less likely to be up to date on their CRC screenings as well as less likely to have ever undergone a CRC screening procedure such as an FOBT, a sigmoidoscopy, or a colonoscopy at all [7]. Reducing these barriers to screening is much more difficult in rural regions, as rural residents are already suffering more disadvantages and are typically more vulnerable populations than those in urban regions[7]. North Dakota (ND) is considered as a rural state of the U.S.ND had one of the lowest rates in the United States in 2016 at 61.8\%, with the lowest screening rate being only $56.8 \%$ in Wyoming[10]. Over the years, ND's CRC screening rate has seen a plateau while several other states' screening rates have been improving[10]. According to America's Health Rankings by the United Health Foundation, ND is ranked 38 out of the 50 states in regards to CRC screening rates[10]. Studying the potential reasons for this low screening rate would aid in helping ND to adjust its screening programs and awareness programs so as to reach more residents and improve CRC health outcomes.In ND, the screening rate for individuals 50 years or younger, for individuals between 50 and 64 years of age, and for individuals' ages 65 years and older is $63.3 \%, 56.8 \%$ and $73.1 \%$, respectively [10]. These statistics comes to a surprise as screening rates for individuals $<50$ years and $>65$ years are higher than the statewide average[10]. However, the screening rate for individuals' ages 50-64 years is 5\% below that of the statewide average[10]. This age group would benefit most from awareness campaigns as well as public health intervention and targeted screening programs.

North Dakota (ND) had the highest incidence of CRC (56.9 per 100,000 population) in the United States according to the 2007 Center for Disease Control and Prevention (CDC) report[11]. Though, barriers contributing to poor screening have been studied at the national level, individual state level studies are rare [12-15]. In this article, we aim to identify the potential factors responsible for the poor screening rate and high incidence of CRC in ND. Assessing the barriers within a rural state such as ND and comparing these to that of the U.S. as a whole would shed some much-needed light on the intricacies plaguing the low screening rates in ND as well as possibly point in the direction of areas of weakness which could benefit from policy development or public health programs.

\section{Materials and Methods}

We utilized the 2010 Behavioral Risk Factor Surveillance System (BRFSS) to find the predictors which could affect the CRC screening for the state of ND and the remaining 49 states.BRFSS is the largest continuously conducted health survey system in the world and is the database of health-related telephone surveys collectingdata of the non-institutionalized US residents regarding their chronic health conditions, health-related risk behaviors, and use of preventative services[16].

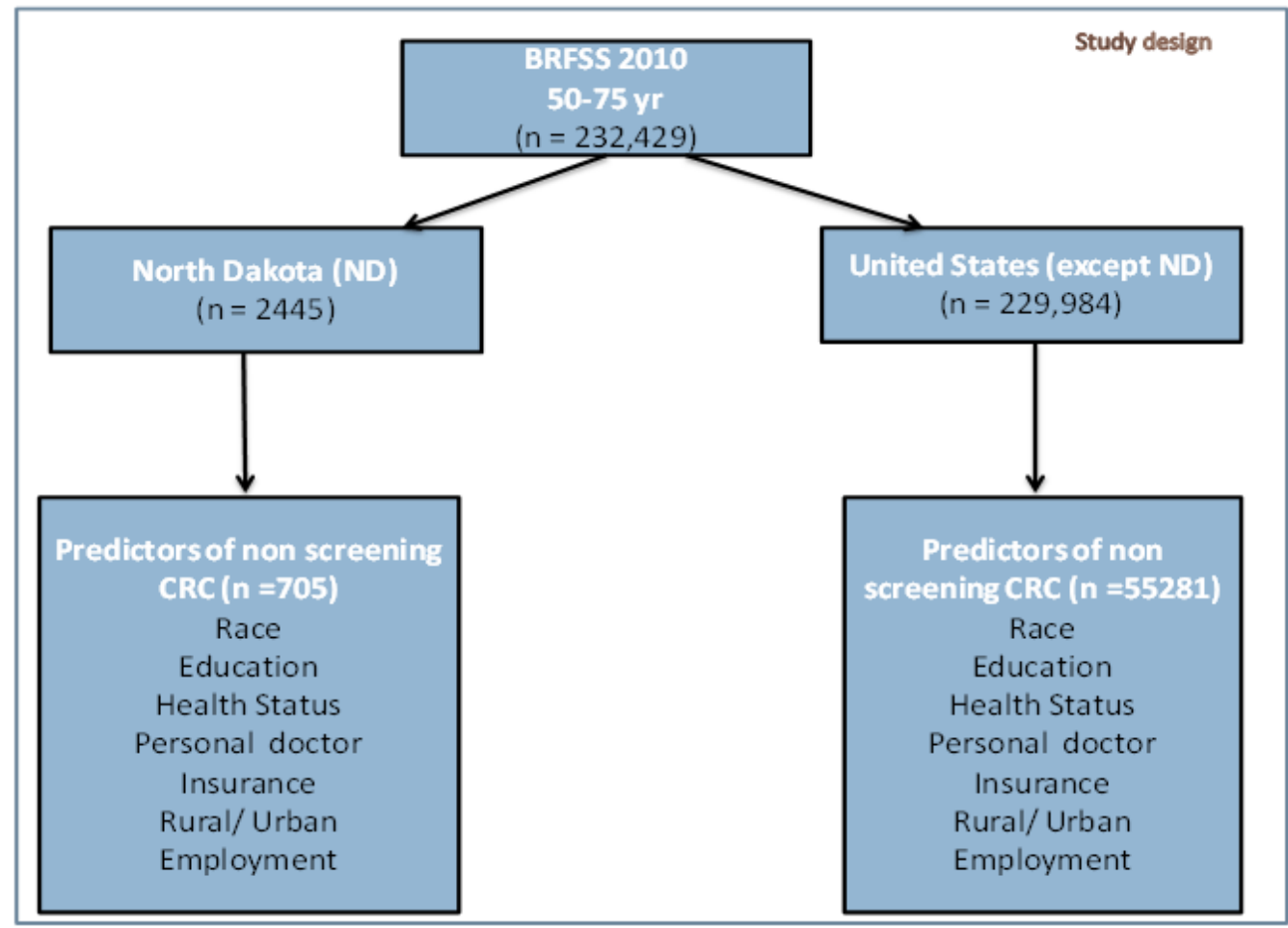

Figure1: Study design of the BRFSS 
We used the CRC screening recommendation guidelines provided by USPSTF, CDC and American Cancer Society (ACS). We used data from 232,429 adults aged between 50 to 75 years from the 2010 BRFSS survey to identify the rate of CRC screening either by using a high-sensitivity fecal occult blood test (FOBT), sigmoidoscopy, or colonoscopy (Figure 1). We computed frequencies as well as adjusted odds ratios (aORs) and 95\% confidence intervals (CIs) using Surveyfreq and Surveylogistic procedures. Statistical software SAS v.9.3 (SAS Institute, Cary, NC) was used to analyze the data in a manner that accounts for the BRFSS's complex sample survey design.

Out of 232,429 adult respondents, 2,445 individuals were from ND and 229,984 were from the rest of the US. Characteristics

Table 1: Characteristics of the US population (except North Dakota) who never received CRC screening

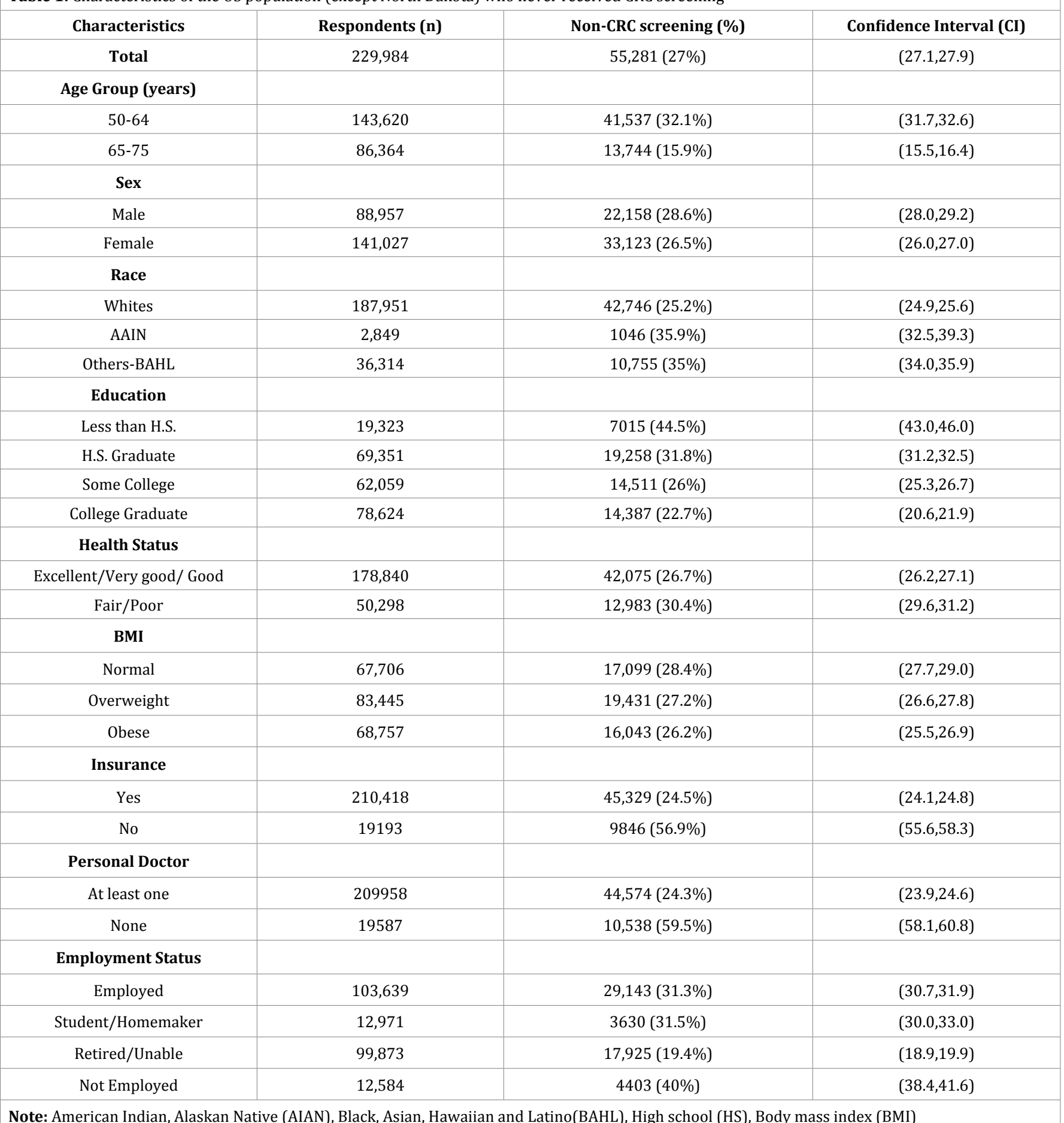

Note: American Indian, Alaskan Native (AIAN), Black, Asian, Hawaiian and Latino(BAHL), High school (HS), Body mass index (BMI) 
Table 2: Characteristics of the North Dakota population who never received CRC screening

\begin{tabular}{|c|c|c|c|}
\hline Characteristics & Respondents (n) & Non-CRC screening (\%) & Confidence Interval (CI) \\
\hline Total & 2445 & $705(32.3 \%)$ & $(30.1,34.5)$ \\
\hline \multicolumn{4}{|l|}{ Age Group (years) } \\
\hline $50-64$ & 1611 & $553(38.3 \%)$ & $(35.6,41.0)$ \\
\hline $65-75$ & 834 & $152(18 \%)$ & $(15.1,20.8)$ \\
\hline \multicolumn{4}{|l|}{ Sex } \\
\hline Male & 978 & $319(35.3 \%)$ & $(31.9,38.6)$ \\
\hline Female & 1467 & $386(29.4 \%)$ & $(26.7,32.1)$ \\
\hline \multicolumn{4}{|l|}{ Race } \\
\hline White & 2326 & $652(31.4 \%)$ & $(29.2,33.5)$ \\
\hline AAIN & 43 & $25(66.9 \%)$ & $(50.5,83.3)$ \\
\hline \multicolumn{4}{|l|}{ Education } \\
\hline Less than H.S. & 120 & $51(50.9 \%)$ & $(40.0,61.8)$ \\
\hline H.S. Grad & 757 & $251(38.2 \%)$ & $(34.2,42.2)$ \\
\hline Some College & 811 & $223(31 \%)$ & $(27.3,34.8)$ \\
\hline College Grad & 754 & $180(25.8 \%)$ & $(22.2,29.5)$ \\
\hline \multicolumn{4}{|l|}{ Health Status } \\
\hline Excellent/Very good/Good & 1985 & $569(32.3 \%)$ & $(29.9,34.7)$ \\
\hline Fair/Poor & 455 & $133(31.8 \%)$ & $(26.8,36.7)$ \\
\hline \multicolumn{4}{|l|}{ BMI } \\
\hline Obese & 750 & $213(32.1 \%)$ & $(28.2,36.0)$ \\
\hline \multicolumn{4}{|l|}{ Insurance } \\
\hline Yes & 2254 & $602(30 \%)$ & $(27.7,32.1)$ \\
\hline No & 186 & $101(62.4 \%)$ & $(54.5,70.4)$ \\
\hline \multicolumn{4}{|l|}{ Personal Doctor } \\
\hline At least one & 2145 & $540(28.1 \%)$ & $(26.0,30.3)$ \\
\hline None & 297 & $165(59.5 \%)$ & $(53.0,66.0)$ \\
\hline \multicolumn{4}{|l|}{ Employment } \\
\hline Employed & 1400 & $466(36.4 \%)$ & $(33.5,39.3)$ \\
\hline Student/Homemaker & 163 & $47(33 \%)$ & $(24.8,41.1)$ \\
\hline Retired/Unable & 796 & $159(22 \%)$ & $(18.7,25.4)$ \\
\hline Not Employed & 76 & $32(47 \%)$ & $(32.7,61.1)$ \\
\hline
\end{tabular}

Note: American Indian, Alaskan Native (AIAN), Black, Asian, Hawaiian and Latino(BAHL), High school (HS), Body mass index (BMI), North Dakota (ND)

of the US and ND populations are noted in(Tables 1,2).Individuals who had never received CRC screening were again stratified into two groups: 50-64-year old and 65-75-year-old individuals. These individuals were then grouped based on ethnicity as White,
American Indian, Alaskan Native (AIAN), Black, Asian, Hawaiian and Latino (BAHL). Education categories included less than high school graduate (never attended school or only kindergarten, elementary [grade 1-8], and some high school [grade 9-11], 
high school graduate, some college or technical school (1-3 years) and college graduate. Health status was divided into two groups: excellent/very good/good, and fair/poor. Weight was stratified according to Body Mass Index (BMI) and divided into three groups: normal (a BMI of 18.5 to 24.99), overweight (a BMI of 25 to 29.99) and obese (a BMI over 30). Individuals with either any health insurance, prepaid plans (health maintenance organizations- HMOs) or government plans were considered as insured and the rest as not insured. Employment status was defined as employed, student/homemaker, retired/unable to work or not employed.

Figure 2 depicts the counties in the U.S. with the highest risk for CRC. Knowledge of these high-risk locations helps to indicate areas with opportunity for specific prevention programs which can be geared towards indicated predictors of non-screening for CRC. According to the CDC, age-adjusted CRC incidence and screening rates in the US are $38 \%$ and $65 \%$, respectively [16].

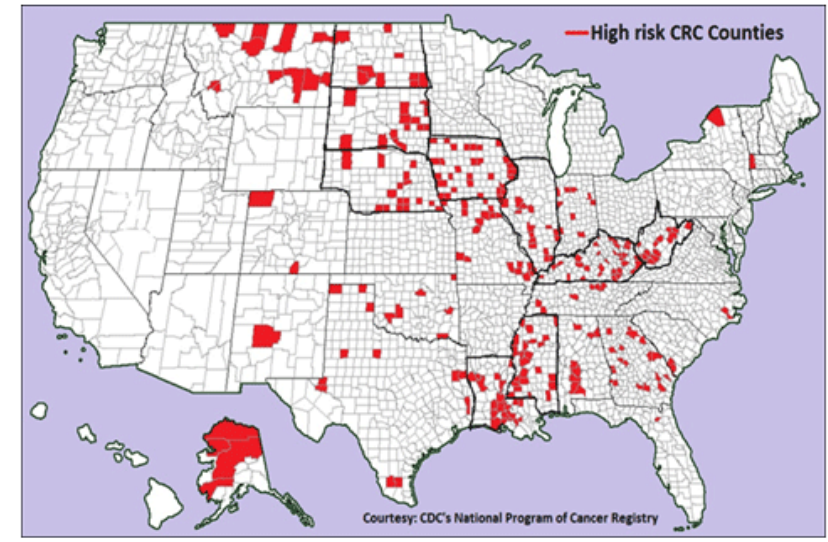

Figure 2: High-risk CRC counties (colored red) in the U.S.

CDC - Centers for Disease Control \& Prevention

\section{Results and Discussion}

The prevalence of screening for CRC was significantly lower among North Dakotans than the rest of the US population (32\% vs. $37 \%$ respectively; $p<0.0001$ ). Demographic characteristics of ND and the U.S. populations are shownin Tables 1, 2.The most significant potential indicators of non-screening for CRC in ND included age, education level, sex, health insurance, employment, and access to a personal doctor. North Dakotans aged 50 to 64 years were more likely to report no screening for CRC than their US-wide counterparts ( $38 \%$ vs. $32 \%$ respectively; $p<0.0001$ ). ND men were more likely to report not screening for CRC than U.S. men overall (35\% vs. $29 \%$ respectively; $p<0.0001$ ). Overall, those without health insurance were less likely to report CRC screening (ND: 62\% vs. US: 57\%). Adjusting for age, race, gender, education, marital status, employment, BMI, having a personal doctor, health insurance, and general health status, ND individuals were significantly less likely to report CRC screening (aOR=0.74; 95\% CI [0.66-0.83]) than the US respondents.

CRC screening in the US is well below the national target[18].
Though the screening rate has improved over the last two decades, a significant gap between the actual and target rates persists [19]. Rural areas are traditionally associated with low CRC screening rates [10]. Given the high incidence of CRC and being a rural state, we decided to compare the CRC screening in North Dakota and compare with the rest of the US. ND was one of the states with the most extreme shortage of primary care physicians with only 40 community hospitals in 2013 [20,21].

The rural location is at inherent limitation and poses a distinct challenge for preventative screening procedures. Ideally, measures to improve screening rates are targeted at all levels including the provider, practice, and patient. The physician workforce remains an integral part of this effort. Directing medical schools that train physicians with an emphasis on family practice targeted towards the rural mission as well asrecruiting physicians who have ties within local rural communities might help to overcome the large shortage of workforce in these areas [22-25]. Granting advanced nurse practitioners with a higher degree of autonomy, especially in medically-underserved areas with physician scarcity could decrease this shortage [26]. Using Electronic Health Records (EHR) to set up reminders and communicate clinician feedback, along with the use of personalized remote cancer risk communication, culturally acceptable navigation plans, defined clear goals, and outreach via telephone and mailed letter communication could improve the adherence and increase rates of CRC [27-30].

Among the patient-related barriers, the absence of health insurance has a significant correlation with screening rates [31]. Though FOBT is relatively inexpensive and has an advantage of self-screening, it has low sensitivity and specificity $[32,33]$. On the contrary, sigmoidoscopy and colonoscopy have better sensitivity and specificity, but are expensive [34]. In addition to high out-ofpocket costs, these factors might decrease the rate of screening colonoscopies which could have significant consequences on CRC-related mortality[35].

One of our study's strengths is the inclusion of a large sample size. Furthermore, information including confounding variables that could potentially affect colorectal screening helps in identification of factors that could be addressedand modified in the future. Additionally, this study also focuses on the counties at risk throughout the US that could help guide policy directed towards vulnerable areas. Lastly, to our knowledge there are no other studies which focus on barriers to screening in a rural state and then compare these to the U.S. as a whole, as well as look at county information in the US. Rural populations are frequently understudied, and the results of this study can benefit people within underserved and vulnerable populations in the rural United States.

There are some limitations of our study worth to mention. BRFSS is based on non-institutionalized adults and not on patient-based data. However, as screening involves adults without symptoms, this might not be very significant. Given that the random telephonic survey, its study design is cross-sectional and 
hence, causality cannot be determined. Given the data which was collected over the telephone, adults without access to a telephone or cell phone were excluded. It was limited to adults speaking English or Spanish. There is a possibility of recall bias and measurement bias. Data for counties with low population were not available. Missing data could limit our study interpretation. Respondents might not give the information in entirety during the self-reporting telephonic conversation, which might lead to questions of the reliability and validity of the data. However, the high sample size of this database might offset this issue.

\section{Conclusions}

The study of non-screening rates in patients with CRC at the state level in comparison with the US gives a unique opportunity to identify possible areas of improvement. Availability of countylevel information helps to direct screening strategies towards high-risk areas. Targeting at-risk populations with high incidence, mortality, and non-screening rates, especially in rural counties, could contribute significantly to aid in improving screening rates. Factors such as unemployment, less than high school education, and lack of personal doctor and health insurance are the potential predictors of non-screening for CRC.

Future studies should target the high-risk counties identified in this study in order to develop effective and customized prevention initiatives in these areas. Additionally, future studies investigating for other potential indicators of non-screening for CRC will help to broaden the literature base and guide future policymaking and public health interventions.

Funding sources: No funding sources.

Disclosures: No competing financial interests exist.

Acknowledgements: We are grateful to Abe Sahmoun, (Director of research affairs, University of North Dakota School of Medicine) for his immense help in statistical analysis and methodology.

\section{References}

1. Jemal A, Bray F, Center, MM, FerlayJ, Ward, E, Forman, D. Global cancer statistics. CA Cancer J Clin.2011;61(2): 69-90. doi: 10.3322/ caac. 20107

2. Key statistics for colorectal cancer. American Cancer Society. https:// www.cancer.org/cancer/colon-rectal-cancer/about/key-statistics. html. Published October 15, 2016.

3. Cancer Stat Facts: Colorectal Cancer. National Cancer Institute. https://seer.cancer.gov/statfacts/html/colorect.html.

4. Colorectal cancer facts \& figures 2017. American Cancer Society. Available at: https://www.cancer.org/content/dam/cancer-org/research/cancerfacts-and-statistics/colorectal-cancer-facts-and-figures/colorectalcancer-facts-and-figures-2017-2019.pdf. Published 2017.

5. Winawer S, Fletcher R, Rex D, Bond J, Burt R, Ferrucci J. Colorectal cancer screening and surveillance: clinical guidelines and rationaleUpdate based on new evidence. Gastroenterology. 2003;124(2):544560.

6. Cancer Screening Rates Missing Targets. National Cancer Institute.
Available at: https://www.cancer.gov/news-events/cancer-currentsblog/2015/screening-targets. Published May 26, 2015.

7. Hughes A, Watanabe-Galloway S, Schnell P, Soliman A. Rural-Urban differences in colorectal cancer screening barriers in nebraska. J Community Health.2015;40(6):1065-1074. doi: 10.1007/s10900015-0032-2

8. Loeve F, Brown ML, Boer R, van Ballegooijen M, van Oortmarssen GJ, Habbema JD. Endoscopic colorectal cancer screening: a cost-saving analysis. J Natl Cancer Inst. 2000;92(7):557-563.

9. $80 \%$ by 2018. National Colorectal Cancer Roundtable. http://nccrt. org/what-we-do/80-percent-by-2018/. Published 2018.

10. Colorectal cancer screening: North Dakota profile. United Health Foundation. Avaialble at: https://www.americashealthrankings.org/ explore/2016-annual-report/measure/colorectal_cancer_screening/ state/ALL. Published 2018

11. Richardson, LC, Tai, E, Rim, SH, Joseph, D, Plescia, M. Vital signs: Colorectal cancer screening, incidence and mortality --- United States, 2002--2010. Morb and Mort Weekly Rep (MMWR). 2011;60(26):884889.

12. Peterson NB, Dwyer KA, Mulvaney SA, Dietrich, MS, Rothman, RL. The influence of health literacy on colorectal cancer screening knowledge, beliefs and behavior. J Natl Med Assoc. 2007;99(10):1105-1112.

13. Arnold CL, Rademaker A, Bailey SC, Esparza JM, Reynolds C, Liu D. Literacy barriers to colorectal cancer screening in community clinics. J Health Commun. 2012;17(3):252-264. doi: 10.1080/10810730.2012.713441

14. Dietrich AJ, Tobin JN, Robinson CM, Cassells A, Greene MA, Dunn VH. Telephone outreach to increase colon cancer screening in medicaid managed care organizations: a randomized controlled trial. Ann Fam Med. 2013;11(4):335-343. doi: 10.1370/afm.1469

15. Redmond Knight J, Kanotra S, Siameh S, Jones J, Thompson B, ThomasCox S. Understanding barriers to colorectal cancer screening in Kentucky. Prev Chronic Dis. 2015;12:E95.

16. About BRFSS. Center for Disease Control and Prevention. https://www. cdc.gov/brfss/about/index.htm. Published 2014.

17. Sabatino SA, White MC, Thompson TD, Klabunde CN. Prevention, Cancer screening test use - United States, 2013. MMWR Morb Mortal Wkly Rep. 2015;64(17):464-468.

18. Colorectal cancer screening, incidence, and mortality--United States. 2002-2010. MMWR Morb Mortal Wkly Rep. 2011;60(26):884-889.

19. Koh HK. A 2020 vision for healthy people.N Engl J Med. 2010;362(18):1653-1656. doi: 10.1056/NEJMp1001601

20. Total hospitals: State health facts, 2015. Retrieved from http://kff. org/other/state-indicator/total-hospitals/. 2016

21. Total professionally active physicians: State health facts, 2015. http:// kff.org/other/state-indicator/total-active-physicians/. 2016

22. Perisetti A, Yendala R. Tu1035 counties with high incidence of colorectal cancer in the United States. Are we screening the right population? Gastroenterology. 2014;146(5):S-734.

23. Rosenblatt RA. A view from the periphery - health care in rural America. N Engl J Med.2004;351(11): 1049-1051.

24. Sekscenski ES, Sansom S, Bazell C, Salmon ME, Mullan F. State practice environments and the supply of physician assistants, nurse practitioners, and certified nurse-midwives. $\mathrm{N}$ Engl J 
Med.1994;331(19):1266-1271.

25. Rabinowitz HK, Diamond JJ, Markham FW, Paynter NP. Critical factors for designing programs to increase the supply and retention of rural primary care physicians. JAMA. 2001;286(9):1041-1048.

26. Iglehart JK. Expanding the role of advanced nurse practitioners--risks and rewards. N Engl J Med.2013;368(20):1935-1941.

27. Baker DW, Brown T, Buchanan DR, Weil J, Balsley K, Ranalli L. Comparative effectiveness of a multifaceted intervention to improve adherence to annual colorectal cancer screening in community health centers: a randomized clinical trial. JAMA Intern Med. 2014;174(8):1235-1241. doi: 10.1001/jamainternmed.2014.2352

28. Wheeler SB, Kuo TM, Goyal RK, Meyer AM, Hassmiller Lich K, Gillen EM. Regional variation in colorectal cancer testing and geographic availability of care in a publicly insured population. Health Place. 2014;29:114-123. doi: 10.1016/j.healthplace.2014.07.001

29. Kinney AY, Boonyasiriwat W, Walters ST, Pappas LM, Stroup AM, Schwartz, et al. Tele health personalized cancer risk communication to motivate colonoscopy in relatives of patients with colorectal cancer: the family CARE Randomized controlled trial. J ClinOncol. 2014;32(7): 654-662. doi: 10.1200/JC0.2013.51.6765

30. Levin TR, Jamieson L, Burley DA, Reyes J, Oehrli M, Caldwell C.
Organized colorectal cancer screening in integrated health care systems. Epidemiol Rev. 2011;33:101-110. doi: 10.1093/epirev/ mxr007

31. Wilper AP, Woolhandler S, Lasser KE, McCormick D, Bor DH, Himmelstein, DU. Health insurance and mortality in US adults. Am J Public Health. 2009;99(12):2289-2295. doi: 10.2105/ AJPH.2008.157685

32. Brenner H, Hoffmeister M, Birkner B, Stock C. Diagnostic performance of guaiac-based fecal occult blood test in routine screening: state-wide analysis from Bavaria, Germany. Am J Gastroenterol.2014;109(3):427-435. doi: 10.1038/ajg.2013.424

33. Imperiale TF, Ransohoff DF, Itzkowitz SH. Multitarget stool DNA testing for colorectal-cancer screening. N Engl J Med. 2014;371(2):187-188.

34. Ladabaum U, Levin Z, Mannalithara A, Brill JV, Bundorf MK. Colorectal testing utilization and payments in a large cohort of commercially insured US adults. Am J Gastroenterol.2014;109(10):1513-1525. doi: 10.1038/ajg.2014.64

35. Wharam JF, Graves AJ, Landon BE, Zhang F, Soumerai, SB, Ross-Degnan D. Two-year trends in colorectal cancer screening after switch to a high-deductible health plan. Med Care.2011;49(9):865-871. doi: 10.1097/MLR.0b013e31821b35d8 